\section{Commentary: Induction immunotherapy for esophageal cancer: A safe start}

\author{
Mark Onaitis, MD
}

Immunotherapy is revolutionizing the care of patients with cancer, and data are gradually emerging regarding its efficacy for each individual cancer type. Of particular relevance to surgeons are studies that investigate the safety and effectiveness of the addition of induction immunotherapy to the CROSS regimen that is standard of care for locally advanced disease. ${ }^{1}$ In lung cancer, induction immunotherapy has been shown in small trials to be safe. ${ }^{2}$ The current paper $^{3}$ examines safety and feasibility of esophageal resection in a cohort of 25 patients with esophageal adenocarcinoma undergoing induction immunotherapy in addition to standard chemoradiation by comparing them with 143 patients who underwent induction chemoradiation without immunotherapy over the same 3 -year time frame. Encouragingly, they found no increased morbidity and mortality in the immunotherapy group.

While this initial report is promising, several unanswered questions remain. These can be categorized into operative questions and oncologic questions. The oncologic questions are fascinating and beyond the scope of the current paper. The patients studied here are part of a phase I/II trial that will begin to demonstrate whether immunotherapy is effective in esophageal adenocarcinoma, which patients may benefit, and what level of expression of PD1/PDL-1 augurs success. Certainly, the high mutation rate of esophageal carcinoma is promising.

The current study begins to answer the operative questions. Although no statistically significant increases in

\footnotetext{
From the Division of Cardiothoracic Surgery, University of California, San Diego, San Diego, Calif.

Disclosures: The author reported no conflicts of interest.

The Journal policy requires editors and reviewers to disclose conflicts of interest and to decline handling or reviewing manuscripts for which they may have a conflict of interest. The editors and reviewers of this article have no conflicts of interest.

Received for publication Dec 8, 2020; revisions received Dec 8, 2020; accepted for publication Dec 9, 2020; available ahead of print Jan 13, 2021.

Address for reprints: Mark Onaitis, MD, Division of Cardiothoracic Surgery, University of California, San Diego, 9300 Campus Point Dr, Mailcode 7892, La Jolla, San Diego, CA 92037 (E-mail: monaitis@ucsd.edu).

J Thorac Cardiovasc Surg 2021;161:844 $0022-5223 / \$ 36.00$

Copyright $(9) 2020$ Published by Elsevier Inc. on behalf of The American Association for Thoracic Surgery

https://doi.org/10.1016/j.jtcvs.2020.12.027
}

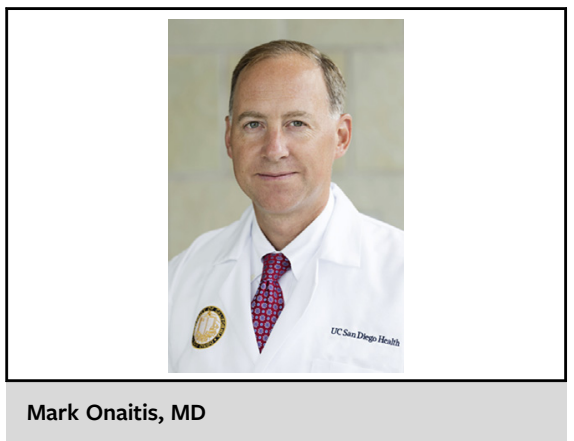

CENTRAL MESSAGE

Induction immunotherapy in conjunction with chemoradiation does not seem to increase perioperative risk.

morbidity were noted, the study is clearly underpowered to identify what may be clinically significant differences. The fact that the patients receiving immunotherapy had a markedly greater rate of major pulmonary complications despite fewer pre-existing pulmonary comorbidities is concerning. Given that pulmonary complications are the largest predictor of perioperative death after esophagectomy and that immunotherapy may cause significant pneumonitis, this issue must be watched closely, as the authors acknowledge. The good news is that $72 \%$ of patients in the immunotherapy group underwent successful minimally invasive esophagectomy, which is known to have one half the pneumonia rate of open cases. The patients thus do not seem to demonstrate the enlarged adherent lymph nodes that have been described to lead to at least a $50 \%$ conversion rate for lung surgery after induction immunotherapy. ${ }^{4}$

All in all, this is a promising start to the induction immunotherapy era for junctional esophageal adenocarcinoma. Safety of surgery leads to a world of possibilities for the future.

\section{References}

1. Van Hagen P, Hulshof MC, van Lanschot JJ, Steyerberg EW, van Berge Henegouwen MI, Wijnhoven BP, et al. Preoperative chemoradiotherapy for esophageal or junctional cancer. N Engl J Med. 2012;366:2074-84.

2. Bott MJ, Yang SC, Park BJ, Adusumilli PS, Rusch VW, Isbell JM, et al. Initial results of pulmonary resection after neoadjuvant nivolumab in patients with resectable non-small cell lung cancer. J Thorac Cardiovasc Surg. 2019;158:269-76.

3. Sihag S, Ku GY, Tan KS, Nussenzweig S, Wu A, Janjigian YY, et al. Safety and feasibility of esophagectomy following combined immunotherapy and chemoradiotherapy for esophageal cancer. J Thorac Cardiovasc Surg. 2021;161:836-43.e1.

4. Chaft JE, Hellman MD, Velez MJ, Travis WD, Rusch VW. Initial experience with lung cancer resection after treatment with T-cell checkpoint inhibitors. Ann Thorac Surg. 2017;104:e217-8. 